\title{
Comparison of gene expression during in vivo and in vitro postnatal retina development
}

\author{
Mu-Gen Liu $\cdot$ Hong Li $\cdot$ Xuming Xu • \\ Colin J. Barnstable • Samuel Shao-Min Zhang
}

Received: 10 March 2008 / Accepted: 5 June 2008 / Published online: 11 July 2008

(C) Humana Press 2008

\begin{abstract}
Retina explants are widely used as a model of neural development. To define the molecular basis of differences between the development of retina in vivo and in vitro during the early postnatal period, we carried out a series of microarray comparisons using mouse retinas. About $75 \%$ of 8,880 expressed genes from retina explants kept the same expression volume and pattern as the retina in vivo. Fewer than $6 \%$ of the total gene population was changed at two consecutive time points, and only about $1 \%$ genes showed more than a threefold change at any time point studied. Functional Gene Ontology (GO) mapping for both changed and unchanged genes showed similar distribution patterns, except that more genes were changed in the GO clusters of response to stimuli and carbohydrate metabolism. Three distinct expression patterns of genes preferentially expressed in rod photoreceptors were observed in the retina explants. Some genes showed a lag in increased expression, some showed no change, and some continued to have a reduced level of expression. An early downregulation of cyclin D1 in the explanted retina might explain the reduction in numbers of precursors in explanted
\end{abstract}

Electronic supplementary material The online version of this article (doi:10.1007/s12177-008-9009-z) contains supplementary material, which is available to authorized users.

M.-G. Liu • H. Li • X. Xu • C. J. Barnstable · S. S.-M. Zhang

Department of Ophthalmology and Visual Science,

Yale University School of Medicine,

New Haven, CT 06520, USA

H. Li $\cdot$ C. J. Barnstable $\cdot$ S. S.-M. Zhang $(\bowtie)$

Department of Neural and Behavioral Sciences, Penn State University College of Medicine,

500 University Drive, H109,

Hershey, PA 17033, USA

e-mail: ssz3@psu.edu retina and suggests that external factors are required for maintenance of cyclin D1. The global view of gene profiles presented in this study will help define the molecular changes in retina explants over time and will provide criteria to define future changes that improve this model system.

Keywords Retina development · Retina explant .

Microarray · Gene expression · Functional genomics · System biology $\cdot$ Rod photoreceptors $\cdot$ Cyclin D1

\section{Introduction}

The retina is an excellent model system to study the central nervous system because of its clear laminar structure, limited number of cell types, accessibility, and easily controlled input signals. Retinal explant cultures have been widely used to study development under strictly controlled conditions [1]. These cultures were developed in the 1950s and have been well established since 1990 [2]. Retina explants have been used extensively for genetic, biochemical, and molecular biological studies of both normal retinal development and retinal pathogenesis [1, 3].

In the appropriate explant culture conditions, the laminar structure of the retina is maintained, the correct cell types are generated and differentiate, and specific synaptic relationships are formed, all of which appear to mimic natural development with high fidelity [2]. On the other hand, clear differences have been observed between development in vivo and in explant cultures. Caffe et al. established explant cultures from PN2 retinas and maintained them for 4 weeks in a serum-free medium [4]. Compared with 4-week-old littermates, the cultured retinas had fewer rows of nuclei in the outer nuclear layer and 
elongated outer segment-like structures. Some photoreceptor-specific proteins, such as interphotoreceptor retinoidbinding protein (IRBP), were distributed differently, although the levels of expression of the IRBP gene were not substantially changed. Green cones were completely absent, and Müller cell numbers were lower. The horizontal cell calcium-binding protein marker calbindin was expressed by the inner retina cellular elements as seen in vivo, but there was some aberrant sprouting of neurites.

It is unclear to what extent the molecular correlates of maturational changes in morphology and differentiation are altered during retina development in vitro. To obtain gene expression profile differences between the early postnatal mouse retinas developing in vivo and in vitro, we have carried out a series of experiments comparing gene expression between retinas collected in vivo and in vitro from PN2 until PN15. Our results show that the large majority of overall gene expression does not differ from that of the retina in vivo, confirming that explant cultures are a suitable system for developmental studies. Some of the differences, such as the decreased expression of cyclin D1, may explain the reduced retina precursor pool expansion and reduced number of mature retinal cells found in vitro. External factors that maintain cyclin D1 expression might be essential for explanted retina development.

\section{Materials and methods}

Animals

Late gestation $\mathrm{C} 57 \mathrm{Bl} / 6 \mathrm{~J}$ mice were purchased from Jackson Laboratory (Bar Harbor, ME, USA). All experiments were complied with the Association for Research in Vision and Ophthalmology Statement for the Use of Animals in Ophthalmic and Vision Research and were approved by the Animal Care and Use Committee of Yale University School of Medicine.

\section{Retina isolation and culture}

Whole retinas were isolated from half of the neonatal litter with at least eight pups at PN1 and cultured [5-7] in UltraCulture $^{\mathrm{TM}}$ (Cambrex Bio Science Rockland, ME, USA) serum-free medium supplemented with $2 \mathrm{mM} \mathrm{L}$ glutamine (two retinas in $1 \mathrm{ml}$ at a 24 -well culture dish, medium was changed everyday) and antibiotics (penicillin, streptomycin, and gentamycin), while the other half of the litter was kept until they reached the desired time points (PN2, PN4, PN6, PN8, PN11, PN15). At least eight retinas from two distinct litters were used for each time point. Whole retinas were dissected, and most of the retinal pigment epithelial (RPE) layer was removed during the isolation. Ribonucleic acid (RNA) was isolated immediately and simultaneously with the cultured retinas from the same litter. Microarray assay, reverse transcriptase (RT) polymerase chain reaction (PCR) confirmation and immunohistochemistry staining experiments were done individually from sample preparation by the same procedure described above.

\section{Generation of mouse retina cDNA microarray}

A set of about 9,216 nonredundant mouse retina expressed sequence tags has been generated from development stages (E13.5, PN1, and adult) in collaboration with Dr. Bento Soares at the University of Iowa [7, 8]. Purified PCR products were printed by the Yale Keck Microarray Core on in-house poly-L-lysine-coated slides utilizing a GeneMachines Omnigrid robotic arrayer (GeneMachines). Of the 9,216 samples in these arrays, 8,880 spots gave valid signals.

\section{RNA isolation and array hybridization}

Detail experimental procedures have been described previously $[7,8]$. Total RNA was isolated by TRIzol (Invitrogen) and purified by RNeasy mini kit (Qiagen). Final concentrations were measured spectrophotometrically using a GeneSpect III (Hitachi). RNA with 280/260 ratio greater than 1.8 was used for microarray hybridization. 3DNA Submicro EX Expression Array Detection Kits (Genisphere) were used for RNA labeling. Two sets of dye-swap hybridization were performed both to provide experimental replicates and to minimize the systemic bias due to dye background variation among slides.

\section{Microarray data collection and statistics analysis}

Slides were scanned on a GenePix 4000B scanner, and the data were manipulated with GenePix software Version 4.0 (Axon Instruments)[7]. Data from different slides were normalized to the median intensity of each slide. One-way analysis of variance and Pearson correlation analysis were performed by Microsoft Excel 2000. Cluster v2.20 and TreeView v1.60 downloaded from http://rana.lbl.gov/ EisenSoftware.htm were used for gene clustering.

\section{Quantitative RT-PCR analysis}

Detailed experimental procedures have been described previously [7, 9]. For each sample, $50 \mu \mathrm{l}$ RT reaction containing $2 \mu \mathrm{g}$ RNA, $10 \mu \mathrm{l} 5 \times$ first-strand buffer (Invitrogen), $5 \mu 110 \mathrm{mM}$ deoxyribonucleotide triphosphate (Invitrogen), $5 \mu \mathrm{l} 0.1 \mathrm{mM}$ dithiothreitol (Invitrogen), $1 \mu \mathrm{l}$ 
RNase-OUT (Invitrogen), and $1 \mu \mathrm{l}$ M-MuLV RT (Roche) was incubated at $37^{\circ} \mathrm{C}$ for $90 \mathrm{~min}$. Real-time PCR used a 25 - $\mu \mathrm{l}$ reaction volume containing $12.5 \mu \mathrm{l}$ Sybr-green supermix (BioRad) with primers and $12.5 \mu \mathrm{l}$ diluted RT product. Annealing temperatures were set at $60^{\circ} \mathrm{C}$ (beta actin at $58^{\circ} \mathrm{C}$ ) for 40 cycles using an iCycler (BioRad). Primer sequences were: Pde6b fwd: 5'-CTG ACG AGT ATG AGG CCA AAG-3', rev: 5'-TAG GCA GAG TCC GTA TGC AGT-3'; Rhodopsin: fwd: 5'-TGC TGT TTT CCT TGG CCT TTG G3', rev: 5'-TCT CTT CAG CAT GCC AGG AAG T-3'; Cend1: fwd: 5'-AAC AAC CTG CAG GTT CAC AGC-3', rev: 5'-ACA GCC ATC TGA ATG CGT GTG T-3'; Bnip3: fwd: 5'-TGG TCA GTT TTG TTG CAG GCA C-3', rev: 5'ACG CCC GAT TTA AGC AGC TTT G-3'; beta-actin: fwd: 5'-GTG GGG CGC CCC AGG CAC CA-3', rev: 5'-CTC CTT ATT GTC ACG CAC GGA TTT C-3'; Nrl: fwd: 5'GTG CCT CCT TCA CCC ACC TTC AGT GA-3', rev: 5'GCG TGC GGC GCC TCT GCT TCA GCC GCA G-3'. For normalization, we measured the nucleic acid in the diluted RT product used for real-time PCR with an Oligreen ssDNA Quantitation Kit (Molecular Probes, O-11492) reading by a fluorescence microplate reader (Ex/Em 485/530 nm). All PCR experimental data are shown as log mean \pm SD. The significance were determined by the Student's $t$ test for each group through Excel 2000 (Microsoft). The level of significance for all statistical analyses was set at $p<0.05$.

\section{Histology and immunohistochemistry staining}

The experimental procedures have been described previously [5]. Whole retinas were dissected at the desired age and fixed by $4 \%$ paraformaldehyde as well as the retinas from littermate in vitro counterparts. After 24-h fixation, tissues were washed three times in PBS and then embedded in paraffin. Four-micrometer sections were cut and processed for hematoxylin and eosin and immunohistochemical staining. Cyclin D1 monoclonal antibody was purchased from Dako Cytomation (M7155, 1:20). Antigen retrieval was done by heating in $95^{\circ} \mathrm{C}$ in $1 \times$ high-pH target retrieval solution (DAKO S3308) for $20 \mathrm{~min}$ and then cool down in room temperature. A fluorescein isothiocyanateconjugated goat anti-mouse $\operatorname{IgG}+\operatorname{IgM}$ (Jackson ImmunoResearch, 115-095-068, 1:200) was used as secondary antibody. Control sections were incubated with secondary antibody alone and showed no cellular labeling.

\section{Results}

Experimental strategies and data collection

To minimize the influences from differences in individual genetic backgrounds, mouse retinas were dissected from
PN1 animals and maintained for $1,3,5,7,10$, and 14 days in culture; littermates were kept with their mothers for the same time periods. The time points of RNA collection for both explant cultures and their live littermates are shown in Fig. 1. Extra retinas from both in vivo and in vitro systems at the same time points were fixed for immunocytochemical analysis.

Because so many genes change their expression levels during development, it is hard to find stably expressed genes that can serve as reliable internal controls. In this study, we first found that a routinely used control gene in cell lines, beta-actin, decreased its level of expression gradually in vivo up to PN15. In samples from explants, we found a significant decrease in beta-actin expression at PN4 and then a more gradual change until it reached the same level as in vivo at PN15 (data not shown). We also measured levels of cyclophilin, a member of a conserved gene family often used as a control in PCR experiments. While cyclophilin was expressed at a constant level in vivo, its level dropped obviously at PN4 in vitro (data not shown). To avoid the problems using such genes as controls, we used an Oligreen ssDNA kit (Molecular Probes) to measure the levels of nucleic acid in the diluted reverse transcript products aliquoted from the samples that were ready to perform RT-PCR and used these values to normalize the RT-PCR results.

Similarity of gene expression pattern during in vivo and in vitro retina development

Two individual data sets were collected from each experiment with a fluorescence intensity greater than 300 in any channel at any time point taken as the spots which could give valid signals. As shown in Fig. 2, among a total of 9,216 spots within the microarray, 8,880 were defined as valid signal spots. When samples from explants were

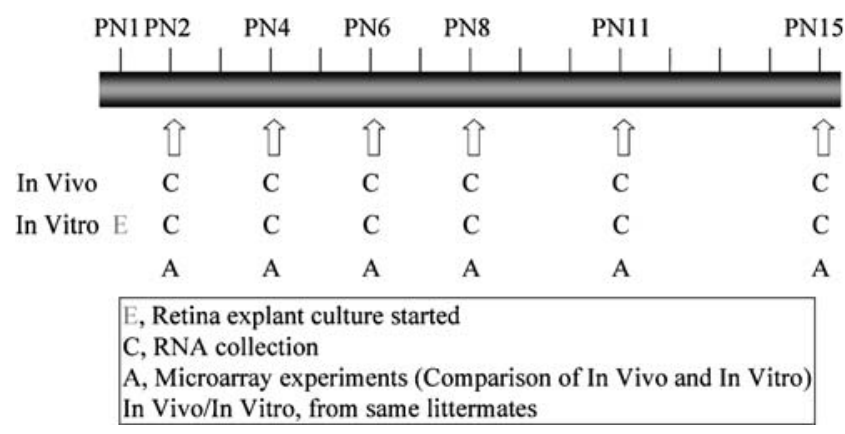

Fig. 1 Strategy of the microarray experiments. The experiment studied six time points during postnatal development. One litter was used for each time point. Whole retinas $(n \geq 8)$ from half pups of the litter were collected at PN1 and cultured in serum-free medium, while the pups of the other half of the litter developed in vivo. When they reached the desired age, total RNA was isolated, respectively, from whole retina of the in vivo and in vitro groups 
Fig. 2 Overview of retinal gene expression in vitro and in vivo. a Numbers of changed and unchanged genes. The cDNA microarray used in this experiments contains 9,216 spots. 8,880 of them were valid signal spots (the spots which have the fluorescence intensity greater than 300 in any channel at any time point). 6,656 of 8,880 remained unchanged. 2,224 genes gained the mean ratio (in vitro vs in vivo) from two datasets greater than twofold (expression increased in in vitro at least twofold) and the ratio from each dataset greater than 1.5 or mean ratio less than 0.5 fold (expression decreased in in vitro at least twofold) and the ratio from each dataset less than 0.67. b Cluster analysis of the changed genes in all time points. Each numerical intensity ratio of in vitro/in vivo was assigned to a color on a scale from red to green, where red represents higher expression in vitro and green represents lower expression in vitro. There were about $25 \%$ genes changed. The first three time points contributed most of the changed genes. Many of them converged to a normal expression level later on. There was also a cluster of genes in the in vitro group, which started with a normal level but then decreased over time compared with in vivo. Many late development stage expression genes were in this group a

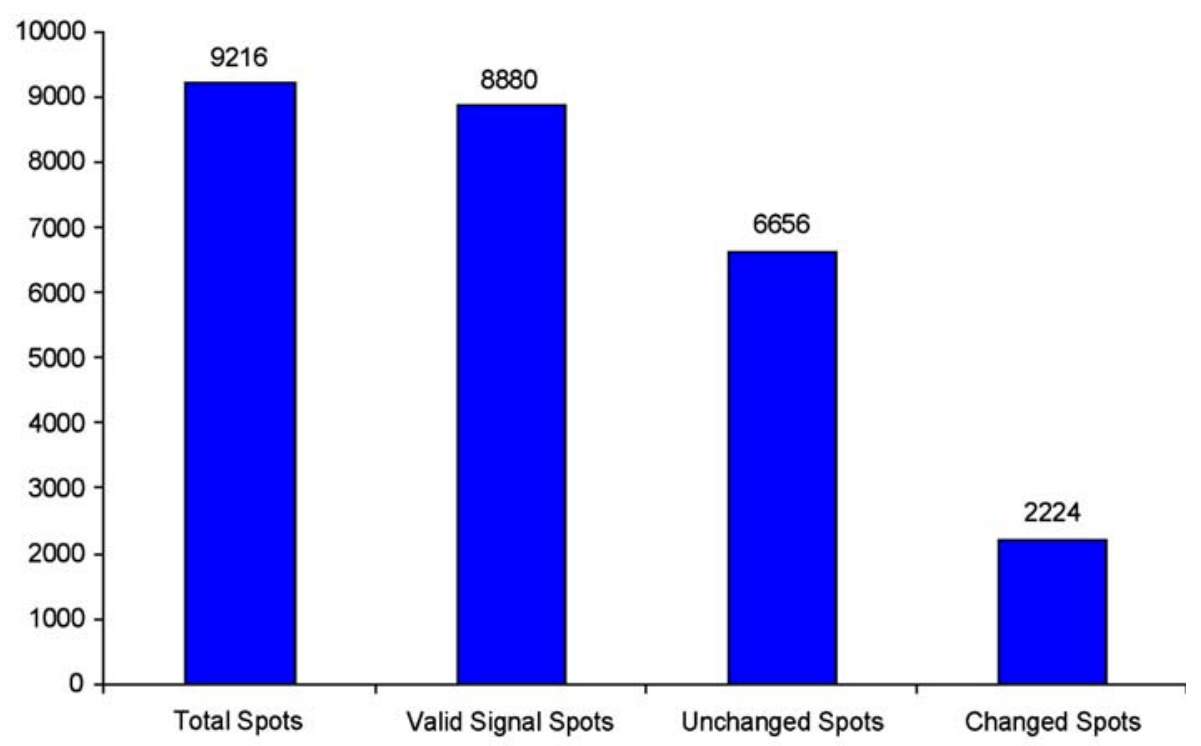

b

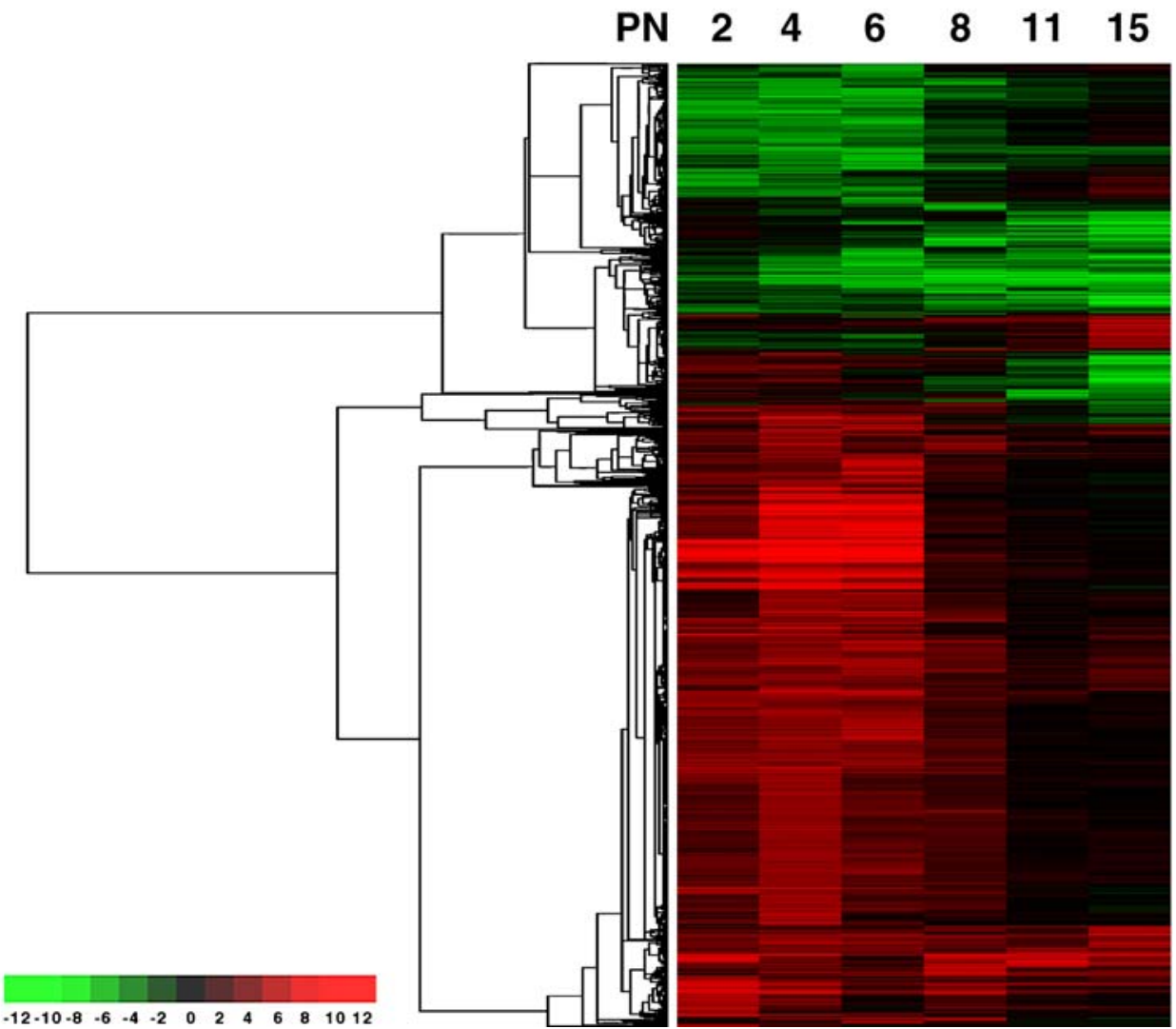

compared with in vivo retina samples, 2,224 genes $(25 \%$ of 8,880 expressed genes, Fig. 2a, Supplemental Material Table 1) gave a mean ratio (in vitro/in vivo) greater than 2 (expression increased in vitro at least twofold) from both data sets with the ratio from each data set greater than 1.5 or a mean ratio less than 0.5 (expression decreased in vitro at least twofold) from both data sets and the ratio from each data set less than 0.67 . This indicated that at least $75 \%$ of all expressed genes which were detected in retina explants kept the same expression volume and patterns as retinas in vivo through this period of postnatal development. Through hierarchical clustering on the basis of expression patterns [10], we noted that there are different expression patterns among the genes changed (Fig. 2b).

To determine whether specific types of genes were in the differentially or similarly expressed populations, a Gene 
Ontology analysis was performed. As shown in Figs. 3 and 4, the majority of functional clusters showed little change in their ratios. Exceptions to this were response to external stimuli increased from $1.7 \%$ to $5 \%$ in the differentially expressed population, stress response increased from $1.2 \%$ to $1.9 \%$, cell-cell signaling increased from $0.4 \%$ to $1.8 \%$, cell differentiation from $0.44 \%$ to $0.81 \%$, cell adhesion from $1.96 \%$ to $2.91 \%$, and cell motility from $0.49 \%$ to $0.97 \%$. A few clusters decreased in the differentially expressed population. Metabolism clusters decreased from $50.8 \%$ to $42.3 \%$, homeostasis from $0.76 \%$ to $0.32 \%$, and development from $3.59 \%$ to $2.58 \%$. Interestingly, functional clusters like signal transduction and cell death clusters showed no changes (Fig. 3). Among the metabolism clusters (Fig. 4), the explant cultures showed increases in carbohydrate metabolism (from $4 \%$ to $8 \%$ ) and nitrogen metabolism (from less than $0.5 \%$ to $2 \%$ ), while lipid metabolism (from
$5 \%$ to $3 \%$ ) and phosphate metabolism (from $11 \%$ to $7 \%$ ) were decreased, indicating that certain metabolic functions are affected during in vitro development.

Distinct gene expression patterns during in vitro retina development

Although expression of the majority of retina genes and their functional clusters are not significantly changed in retina explant cultures, about 25\% (2,224 genes) of expressed genes are altered under the minimal change criteria described above. To identify the genes with more significant changes during in vitro retina development, we selected a criterion whereby a gene had to change in the same direction at more than two neighboring time points. Just more than 500 genes (less than $6 \%$ of total expressed population) were identified by this criterion (Fig. 5), and
Fig. 3 GO comparison between changed and unchanged gene groups. GO comparisons in all genes between changed (a) and unchanged (b) gene groups: The GO functional subgroups of the annotated genes were very similar between changed and unchanged gene groups, except the response to external stimulus and cell-cell signaling groups a

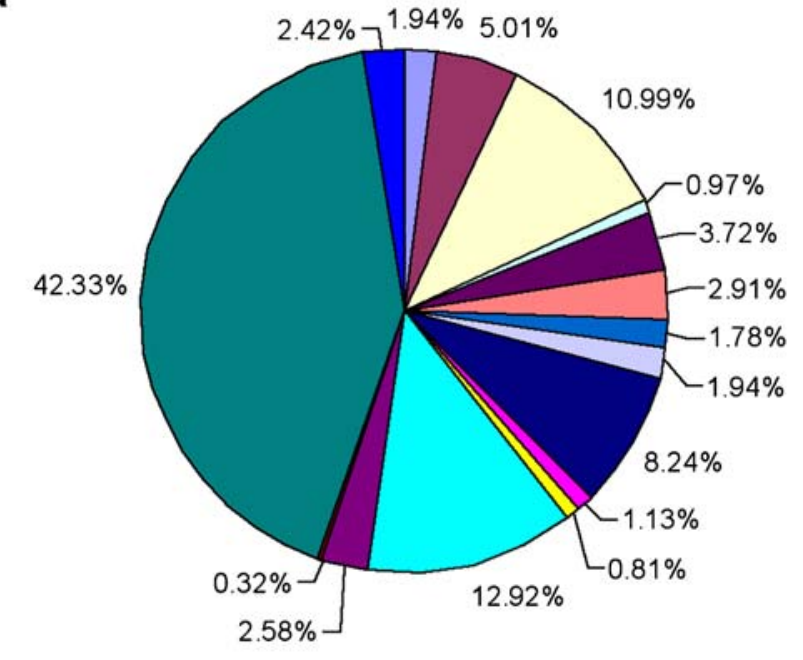

b

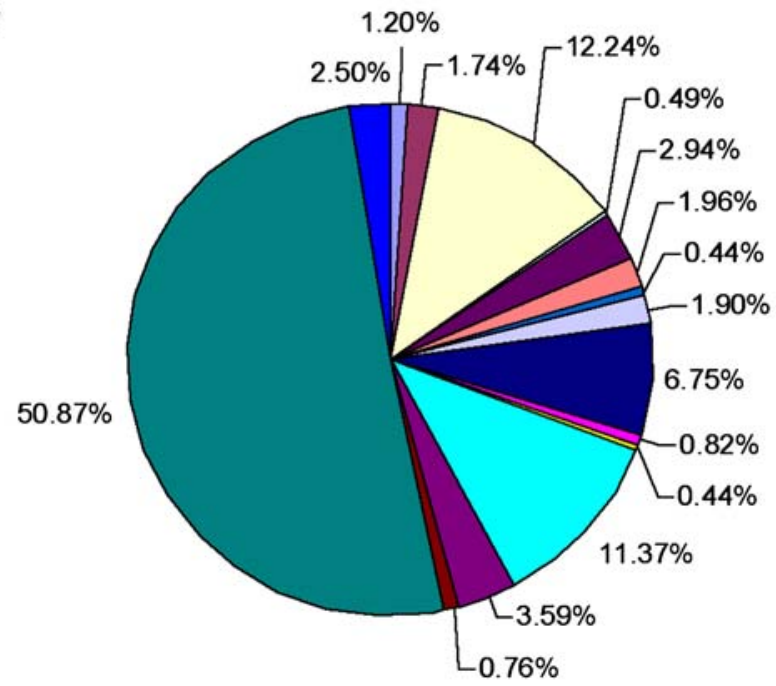

$\square$ Stress response

- Response to external stimulus

$\checkmark$ Signal transduction

$\square$ Cell motility

- Cell cycle

- Cell adhesion

Cell-cell signaling

$\square$ Cell death

- Cell organization and biogenesis

$\square$ Cell growth and proliferation

$\square$ Cell differentiation

$\square$ Transport

- Development

- Homeostasis

Metabolism

- Others 


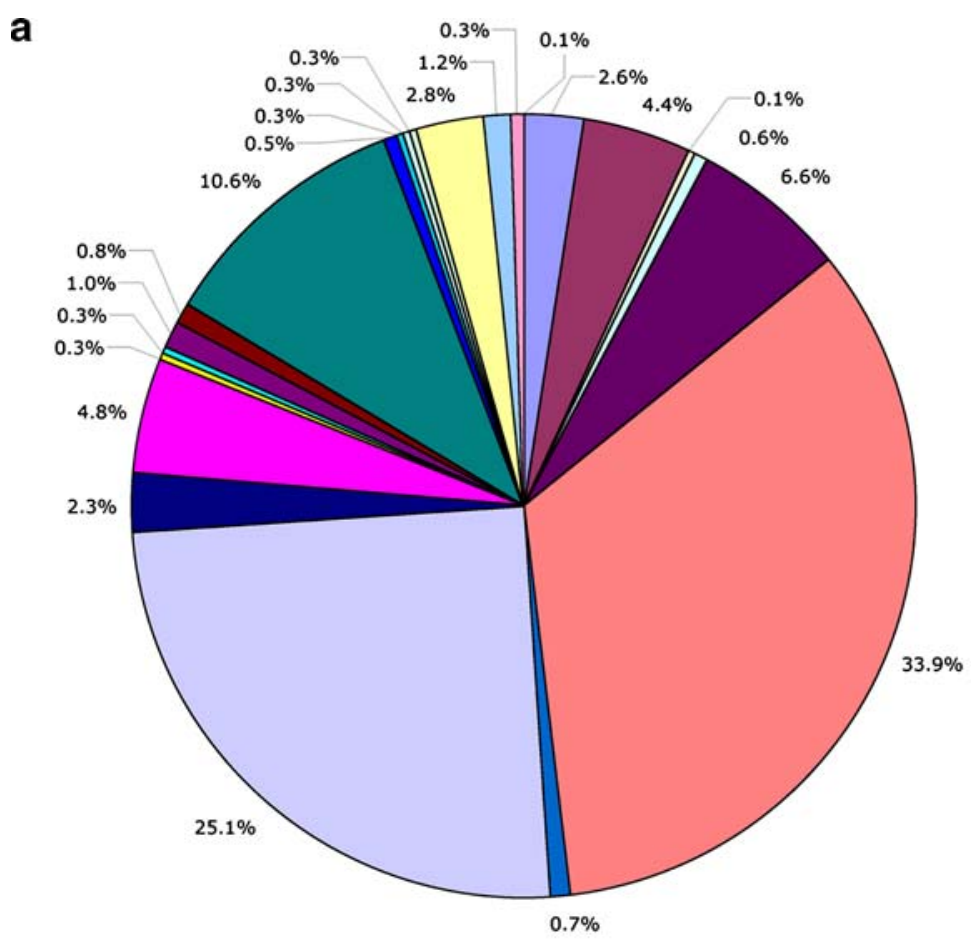

b

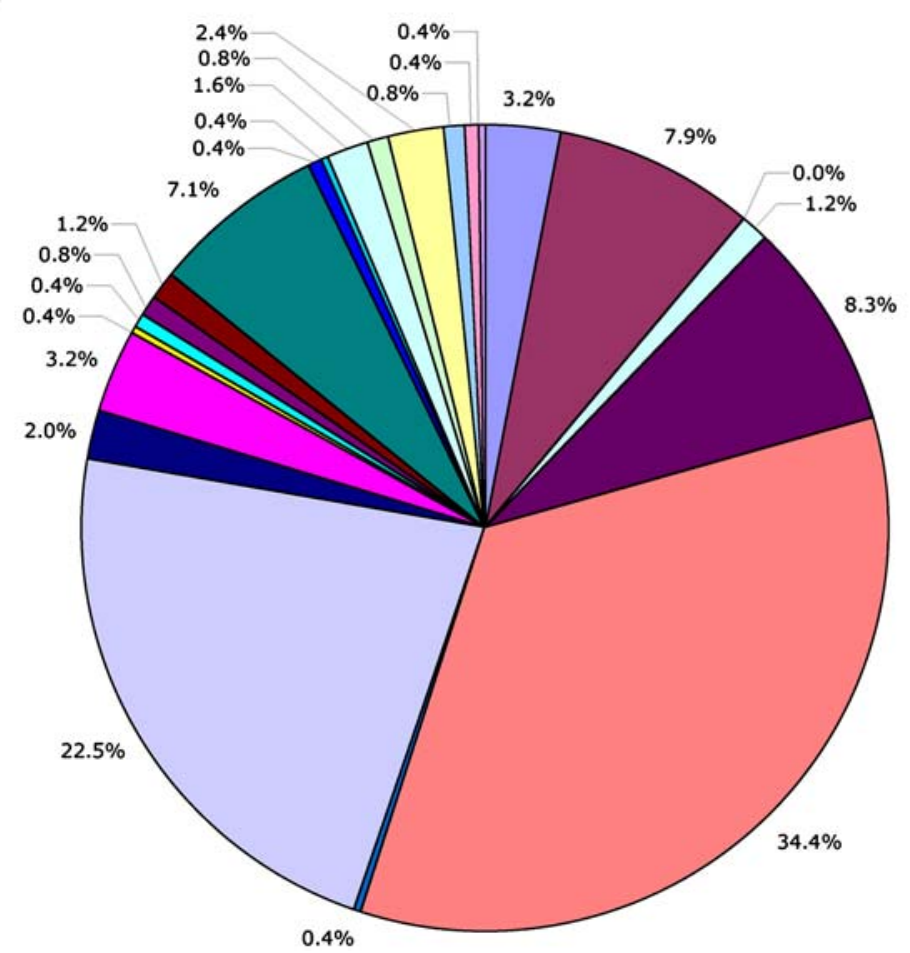

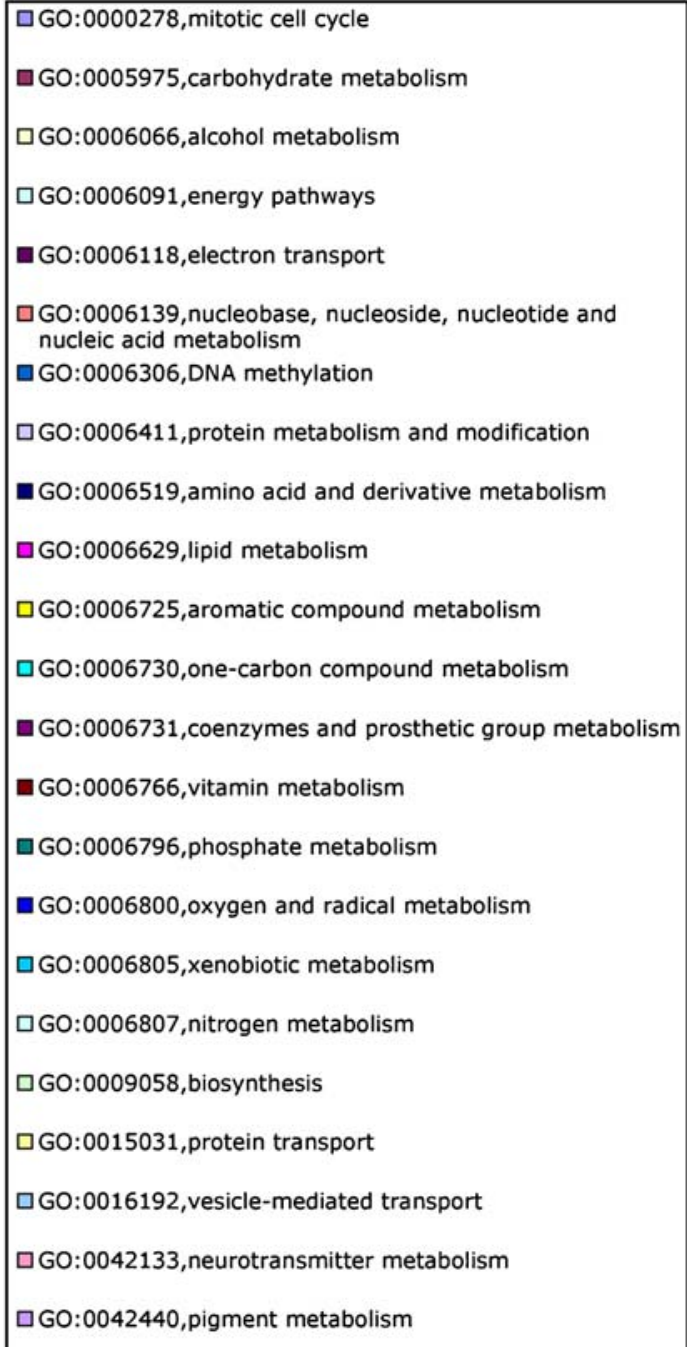

Fig. 4 GO comparison in metabolism subgroups between changed (a) and unchanged (b) gene groups. The GO subgroups of metabolism were very similar between changed and unchanged gene groups, except carbohydrate metabolism, phosphate metabolism, and neurotransmitter metabolism

development compared with in vivo. Interestingly, 404 of these genes showed a change in expression within the first $24 \mathrm{~h}$ of explant culture (Fig. 5). 

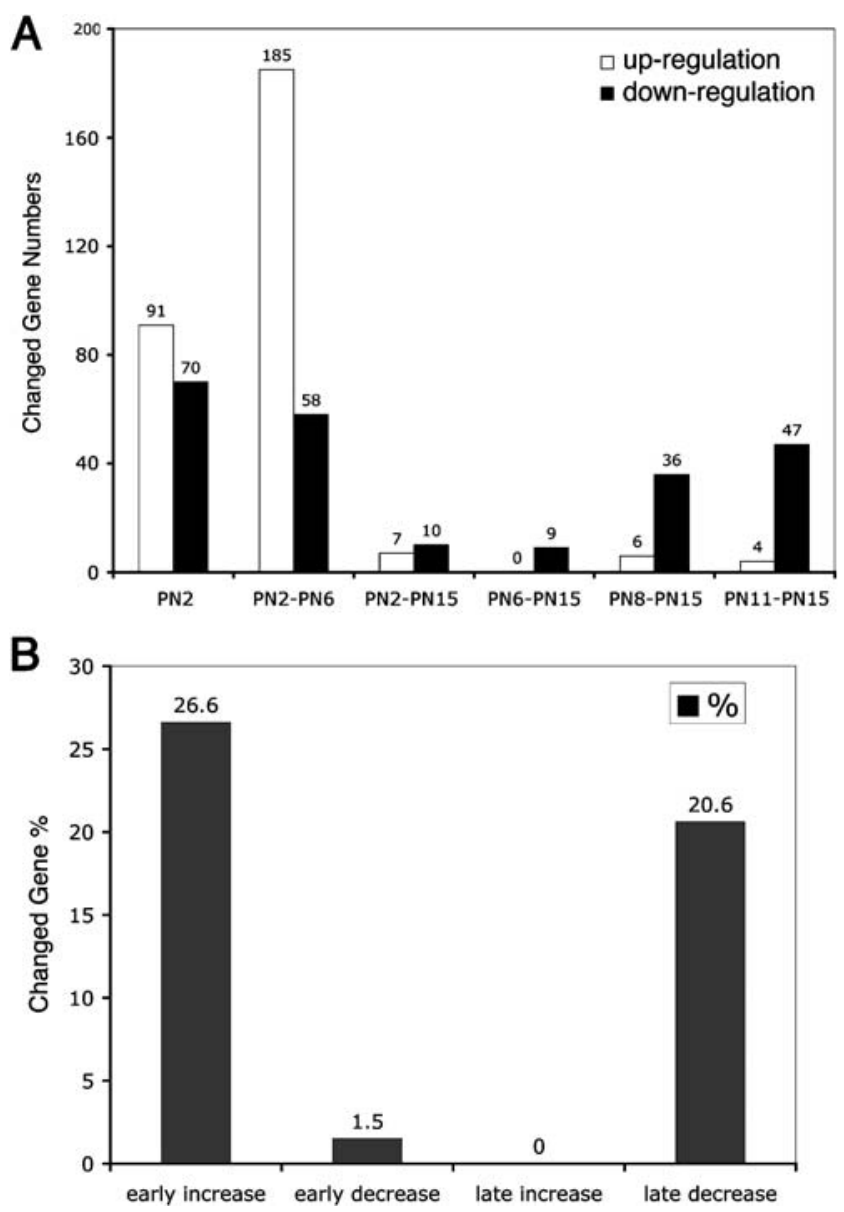

Fig. 5 Temporal patterns of increased or decreased gene expression during in vivo and in vitro development. The peak numbers of changed genes occurred at early time points. Upregulated genes were more frequent than the downregulated genes at the early time points, and downregulated genes more frequent at the late time points. Only a few genes changed throughout the observed time window

To examine the types of genes that showed a more substantial change in retinal explants, we used a more stringent criterion of a threefold change in expression at any time point. Five hundred eighteen genes (about 5\%) among

Table 1 Retina expressed genes and changed genes in vitro

\begin{tabular}{lccc}
\hline Criteria & Gene numbers & Percent unchanged & Percent changed \\
\hline Total & 8,880 & 100 & 0 \\
A & 2,224 & 74.9 & 25.1 \\
B & 518 & 94.2 & 5.8 \\
C & 109 & 98.7 & 1.3 \\
\hline
\end{tabular}

$A$ Mean ratio (in vitro/in vivo) greater than 2 (expression increased in vitro at least twofold) from both data sets with the ratio from each data set greater than 1.5 or a mean ratio less than 0.5 (expression decreased in vitro at least twofold) from both data sets and a ratio from each data set less than 0.67. $B$ Based on the criterion in A and gene changed in the same direction at more than two neighboring time points. $C$ Based on the criterion in $\mathrm{B}$ and at least at one time point more than threefold increase or decrease. the 8,880 expressed genes fell into this category. One hundred forty-five of these were either upregulated or downregulated by the first $24 \mathrm{~h}$ in culture (Supplemental Material Table 2). Just more than half of these 145 genes (75 or $51.7 \%$ ) are currently of unknown function. About $27.1 \%$ of the other 70 genes are known and fell into the functional classes of signaling proteins and transcription. Genes in the retina explants that changed as early as $24 \mathrm{~h}$ after culture through the first three time points included downregulation of Map4k5, the most upstream member of the mitogen-activated protein kinase signaling pathway, upregulation of Yyl, a factor possessing both transcriptional and nontranscriptional properties, and downregulation of two retina genes with known signaling functions, Nr2e3 and Tbx2.

It is interesting to note that about $8.6 \%$ of changed genes were in the functional category of stress response. These

Table 2 Distribution of gene changed during in vitro/in vivo retina development

\begin{tabular}{|c|c|c|c|c|c|c|c|c|}
\hline & \multicolumn{4}{|c|}{ Early stage (fold) } & \multicolumn{4}{|c|}{ Late stage (fold) } \\
\hline & $>2$ & $>3$ & $<2$ & $<3$ & $>2$ & $>3$ & $<2$ & $<3$ \\
\hline Total & 274 & 73 & 127 & 3 & 9 & 2 & 91 & 19 \\
\hline Adhesion & 3 & 1 & 1 & 0 & 1 & 0 & 4 & 2 \\
\hline Angiogenesis & 1 & 0 & 0 & 0 & 0 & 0 & 3 & 0 \\
\hline Apoptosis & 3 & 0 & 2 & 0 & 0 & 0 & 2 & 0 \\
\hline Carbohydrate metabolism & 0 & 0 & 1 & 0 & 2 & 1 & 2 & 1 \\
\hline Cell cycle & 7 & 2 & 6 & 1 & 0 & 0 & 0 & 0 \\
\hline Chromatin & 2 & 1 & 8 & 0 & 0 & 0 & 1 & 0 \\
\hline Cytoskeleton & 7 & 1 & 3 & 0 & 0 & 0 & 7 & 2 \\
\hline Development & 1 & 1 & 0 & 0 & 0 & 0 & 4 & 2 \\
\hline DNA metabolism & 2 & 1 & 3 & 0 & 0 & 0 & 0 & 0 \\
\hline Exocytosis & 0 & 0 & 0 & 0 & 0 & 0 & 1 & 0 \\
\hline Extracellular matrix & 0 & 0 & 1 & 0 & 0 & 0 & 0 & 0 \\
\hline Immune response & 4 & 1 & 0 & 0 & 0 & 0 & 2 & 0 \\
\hline Iron metabolism & 1 & 1 & 0 & 0 & 0 & 0 & 0 & 0 \\
\hline Lipid metabolism & 8 & 2 & 2 & 0 & 1 & 0 & 0 & 0 \\
\hline Migration & 1 & 1 & 0 & 0 & 0 & 0 & 0 & 0 \\
\hline Neurotransmitter metabolism & 9 & 1 & 3 & 0 & 0 & 0 & 10 & 4 \\
\hline Redox & 3 & 2 & 8 & 1 & 0 & 0 & 0 & 0 \\
\hline Phototransduction & 2 & 0 & 0 & 0 & 0 & 0 & 5 & 2 \\
\hline Pigment metabolism & 0 & 0 & 0 & 0 & 0 & 0 & 1 & 0 \\
\hline Protein metabolism & 8 & 1 & 4 & 0 & 0 & 0 & 1 & 1 \\
\hline Pyrimidine metabolism & 0 & 0 & 1 & 0 & 0 & 0 & 0 & 0 \\
\hline Purine metabolism & 1 & 1 & 0 & 0 & 0 & 0 & 0 & 0 \\
\hline RNA metabolism & 0 & 0 & 4 & 0 & 0 & 0 & 0 & 0 \\
\hline RNA splicing & 0 & 0 & 3 & 0 & 0 & 0 & 1 & 0 \\
\hline RNA binding & 2 & 2 & 4 & 0 & 0 & 0 & 1 & 0 \\
\hline Signaling and transcription & 28 & 1 & 19 & 1 & 0 & 0 & 9 & 2 \\
\hline Stress response & 4 & 0 & 0 & 0 & 0 & 0 & 0 & 0 \\
\hline Transport & 5 & 2 & 6 & 0 & 1 & 0 & 3 & 0 \\
\hline Ubiquitination & 2 & 0 & 1 & 0 & 0 & 0 & 0 & 0 \\
\hline Unknown & 170 & 51 & 47 & 0 & 4 & 1 & 34 & 3 \\
\hline
\end{tabular}

Early stage, PN2-PN6; late stage, PN8-PN15 
included upregulation of Hspa1l, Nxn, and Nfat5 and downregulation of $\mathrm{Ckb}$ (Supplemental Material Table 2). About $11.4 \%$ of cell cycle-related genes changed, including the downregulation of Ccnd 1 and Bccip and upregulation of Cdc25a, Igfbp5, and Cdc20. Since many of these genes are known to be regulated in other ischemic tissues [11, 12], our results suggest that an acute ischemic response occurred immediately after the retina was explanted.

When we compared changes in gene expression in early and late phases of retinal development, we found the a majority of changes were increases in the early stages but decreases in the later stages. Functional analysis of those genes (Table 2) showed that genes related to functional clusters of cell cycle, stress response, lipid metabolism, chromatin, redox, and protein metabolism were changed in the early stages and genes related to functional clusters of phototransduction, carbohydrate metabolism, and development were changed in the later stages. A similar number of functional categories of cytoskeleton, neurotransmitter metabolism, signaling, and transduction showed differential expression at both stages (Table 2). The results suggest that distinct changes in patterns of gene expression occur during in vitro retina development.

Consistency of gene expression through the whole in vitro developmental stages

Among the 2,224 changed genes, only 17 showed a consistent change at all stages of in vitro development. Seven of the genes were upregulated, while ten were downregulated (Table 3). Bnip3, a proapoptotic gene, shows a high expression level through all the stages detected, and these changes are confirmed by RT-PCR analysis from an independent experiment (Fig. 6). Others, such as ischemia/hypoxia-inducible gene, Ero11, and Gpil, are also kept high levels during in vitro retina development (Table 3). Both genes are involved in carbohydrate metabolism, suggesting that an imbalance of energy supply might occur during the in vitro retina development.

Among the ten downregulated genes, Calb2 gene (Calretinin) was significantly reduced in the retina explants, suggesting that it might have some effects on amacrine cell development. Two hemoglobin genes are also significantly reduced in this group, reflecting a contamination of blood cells in the samples directly from in vivo retina and much less in cultured retina (Table 3).

Genes expressed later in development and rod maturation in retina explants

One of the major features of postnatal rodent retina development is the formation and differentiation of rod photoreceptors, cells that eventually constitute more than $85 \%$ of the total retinal cell number. In a previous study [7], a total of about 170 genes from our retina developmental gene expression spectrum database passed a filter that defined them as late developmental stage-expressed genes. Since rod photoreceptors develop almost exclusively after birth, most rod-related genes are included in this group. A

Table 3 Gene changed through all in vitro development stages

\begin{tabular}{|c|c|c|c|c|c|c|c|c|c|}
\hline \multirow[t]{2}{*}{ ID } & \multirow[t]{2}{*}{ Unigene } & \multirow[t]{2}{*}{ Gene name } & \multirow[t]{2}{*}{ Functions } & \multicolumn{6}{|c|}{ Mean ratio (in vitro/in vivo) } \\
\hline & & & & $\mathrm{P} 2$ & $\mathrm{P} 4$ & P6 & $\mathrm{P} 8$ & P11 & $\mathrm{P} 15$ \\
\hline BE988698 & Mm.2159 & Bnip3 & Apoptosis & 5.32 & 5.18 & 2.17 & 6.76 & 6.84 & 3.24 \\
\hline BE951831 & Mm.589 & Gpi1 & Carbohydrate metabolism & 6.68 & 5.14 & 2.98 & 4.06 & 2.53 & 2.17 \\
\hline BE952366 & Mm.273874 & Pfkp & Carbohydrate metabolism & 6.67 & 5.21 & 2.87 & 4.4 & 4.04 & 2.88 \\
\hline BE987340 & Mm.141936 & Igfbp2 & Proliferation & 6.11 & 4.27 & 2.03 & 6.64 & 5.71 & 4.27 \\
\hline BE953589 & Mm.323218 & EST & Unknown & 4.84 & 7.44 & 2.44 & 7.7 & 3.17 & 3.09 \\
\hline BE985366 & Mm.30649 & C330008K14Rik & Unknown & 2.66 & 3.77 & 3.02 & 5.76 & 2.56 & 2.63 \\
\hline BF461745 & Mm.307846 & Rpl22 & Unknown & 2.15 & 2.47 & 2.31 & 2.36 & 2.29 & 2.5 \\
\hline BE954252 & Mm.2755 & Calb2 & $\mathrm{Ca}^{2+}$ binding & 0.26 & 0.18 & 0.17 & 0.11 & 0.07 & 0.05 \\
\hline BE985972 & Mm.2319 & Stmn3 & Cytoskeleton & 0.46 & 0.38 & 0.17 & 0.24 & 0.18 & 0.28 \\
\hline BE983700 & Mm.196110 & Hba-al & Hemoglobin & 0.35 & 0.22 & 0.12 & 0.05 & 0.05 & 0.07 \\
\hline BF466172 & Mm.288567 & Hbb-b1 & Hemoglobin & 0.36 & 0.12 & 0.13 & 0.06 & 0.11 & 0.07 \\
\hline BE951473 & Mm.153272 & Tgfb1i4 & Migration & 0.38 & 0.39 & 0.23 & 0.38 & 0.37 & 0.49 \\
\hline BF463410 & Mm.282800 & Sncg & Signaling & 0.46 & 0.15 & 0.17 & 0.06 & 0.11 & 0.05 \\
\hline BE950156 & Mm.6667 & Ssbp4 & Unknown & 0.48 & 0.43 & 0.5 & 0.43 & 0.41 & 0.47 \\
\hline BE982316 & Mm.289693 & 2410025L10Rik & Unknown & 0.44 & 0.39 & 0.42 & 0.22 & 0.21 & 0.25 \\
\hline BF461637 & Mm.24652 & 3321401G04Rik & Unknown & 0.25 & 0.3 & 0.25 & 0.46 & 0.46 & 0.43 \\
\hline BF463492 & Mm.162407 & 2900024D24Rik & Unknown & 0.38 & 0.17 & 0.17 & 0.05 & 0.19 & 0.07 \\
\hline
\end{tabular}




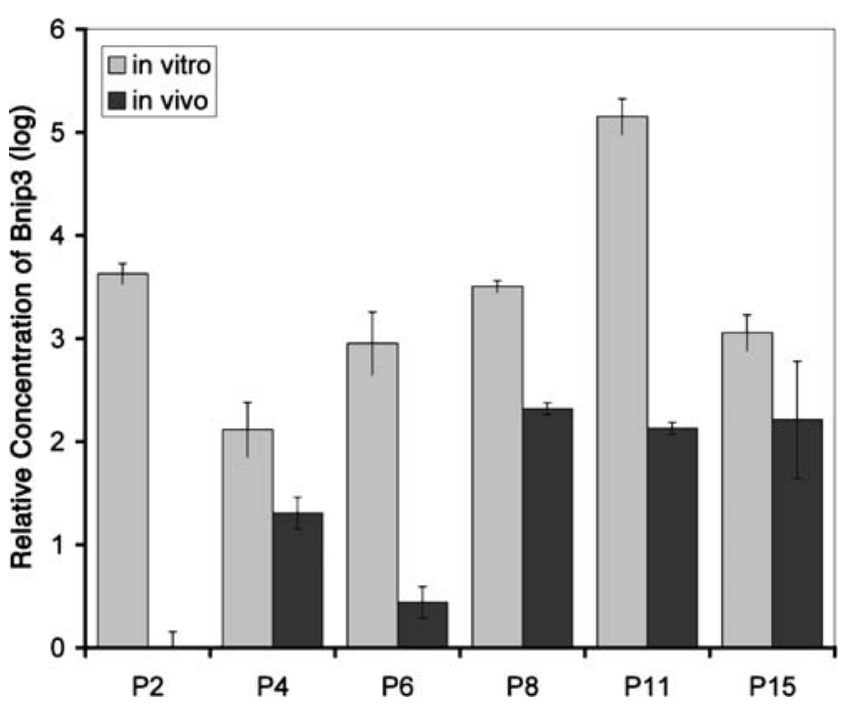

Fig. 6 RT-PCR detection of Bnip3 gene expression during in vivo and in vitro retina development. The expression level of Bnip3 at PN2 in vivo was set to a value of 1 . At all time points, a higher level of Bnip3 was expressed in vitro compared with in vivo. From PN2 through PN11, this difference was highly significant, $p \leq 0.01$, and, though less, remained significant at PN15, $p<0.05$

total of 78 genes were found among the 2,224 lateexpressed genes in this study that varied in expression between in vitro and in vivo retinas. The overview of the 78 late expressed genes displayed in Fig. 7 shows that at early time points, more of the 78 genes increased their expression in vitro, while later time points, more show decreased expression (Fig. 7a). About $80 \%$ of the 78 late-expressed genes have the same temporal expression patterns in vitro as in vivo during the late stages, although some of them achieve a lower final level of expression, such as Rho and Pde6b. Others finally catch up to the same expression level as in vivo by the end of the time period examined. On the other hand, some genes related to Müller glia cells, such as Glu1 (Glutamate synthase), are also significantly reduced during later in vitro retina development (Supplemental Material Table 3), suggesting that the numbers of Müller glia cells might be reduced in these cultures.

As a verification of the microarray results, we first took two retinal genes, Rhodopsin (Rho) and Neural retina leucine zipper ( $\mathrm{Nrl})$, and calculated the intensity of the Rho (BE982526) and Nrl (BF464350) spot labeling in microarrays and compared this with RT-PCR results from an independent experiment. Normalized by slide intensity median, the intensity data showed both a late expression pattern of Rho and a reduced expression level in vitro (Fig. 7b). RT-PCR for Rho and quantitative RT-PCR confirmed the late expression pattern of Rho with an onset of expression at about PN6 (Fig. 7c). It also confirmed the reduced expression level of Rho at late time points. $\mathrm{Nrl}$ [13] was reduced in retina explants during early stages (Fig. 7d), and quantitative RT-PCR also confirmed the similar patterns of gene expression (Fig. 7e).

To have an overall view of retina-specific gene expression during in vitro retina development, we analyzed the expression of 17 genes that were preferentially expressed in rod photoreceptors, as shown in Fig. 8. Three groups can be defined on the basis of their expression patterns and their ability to reach the same expression level as in vivo. Group I (Fig. 8a) includes Rom1, Nrl, Tulp1, Prph2, Elovl4, and Rcvrn and shows decreasing expression level in the early stage in culture but reaches the same level as in vivo at later stage; group II (Fig. 8b) includes Rbp3, Mpp4, Gng1, Abca4, and Aipl1 and shows no significant changes during the in vitro development; group III (Fig. 8c) includes Sag, Kcnj14, Vtn, Rpgrip1, Pde6b, and Rho and shows decreasing expression levels from the early to later stages or reduced levels in the later stages. Since members of each group are known to be rod specific, and the results suggest that multiple mechanisms might be involved in rod maturation during in vitro retina development.

\section{Early withdrawal of cyclin D1 in retina explants}

Cell cycle-related genes were significantly changed during early retina development in vitro, suggesting that expression of these genes might be a key step in regulating the number of postmitotic neurons or the size of the retinal progenitor cell pool. Cyclins and their associated kinases have been considered as the most important elements for cell cycle control in many tissues including in the retina [14-16]. We have summarized all the cell cycle-related genes expressed in this experiment in Fig. 9a. Most of the genes were changed in the early stage in retina explants but reached the same expression level at later stages as in vivo (Fig. 9a). Cyclin D1 is reduced substantially in the culture system from microarray gene expression profiles (Fig. 9a). Confirmation by quantitative RT-PCR of cyclin D1 shows similar results from an independent experiment (Fig. 9b). To test whether cyclin D1 protein showed changing patterns of expression during retina development, we examined sections of retinas from PN2 to PN15 using anti-cyclin D1 antibody. As shown in Fig. 8c, more cyclin D1-positive cells were found at PN2 in the inner parts of the outer retinal layer than at any other later time points both in vivo and in vitro. The in vivo retina had more cyclin D1-positive cells than in vitro at PN2. In retinal explants, cyclin D1 was barely detectable by PN4, whereas it was detected at both PN4 and PN6 in the retina in vivo (Fig. 9c). This indicates an early withdrawal of cyclin D1 in the retina explants and was probably responsible for reducing the retina progenitor pools during the postnatal period. 


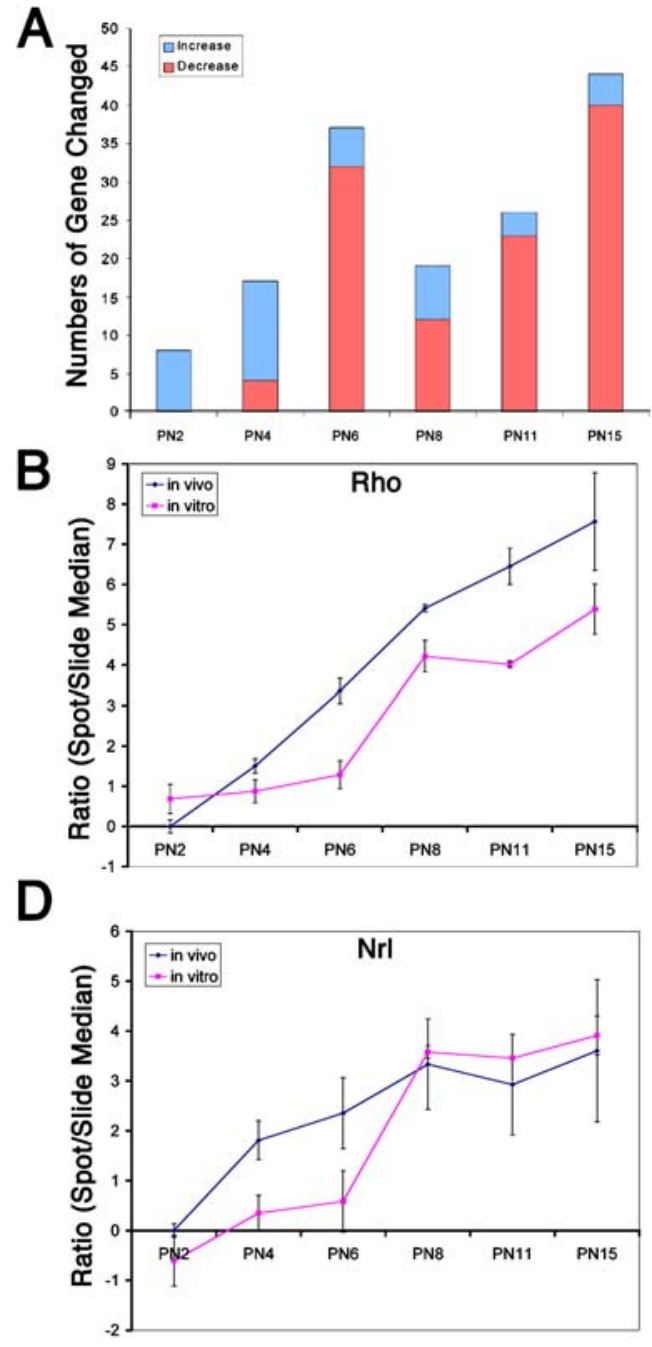

Fig. 7 Changing pattern of expression in late expressed genes. a Overview of 78 late expressed genes which at early time points showed more increases while at later time points showed more decreases. b Two-channel (in vitro and in vivo) $\log _{2}$ intensity of Rhodopsin (Rho) gene (BE950188) in microarray, normalized by slide median intensity. PN2 in vivo intensity normalized was set as 1 . The result showed both late expression pattern of Rhodopsin and the reduced expression level in vitro at the late time points. c Quantitative RT-PCR result of Rho, confirming the late expression pattern of Rho. PN2 in vivo expression level was set as 1 . Rho showed reduced expression levels at late time points $(p<0.001$ at PN11 and PN15),

\section{Discussion}

Retinal explants are good models of retina development in vivo

No culture system can be an exact mimic of in vivo development. Understanding the overall similarities and differences between in vivo and in vitro development is important for interpreting studies using cultured tissue. Cultured tissue is also the only way that some studies, such as those of human retinal development, can be carried out. The comparison of the patterns of gene expression in vitro

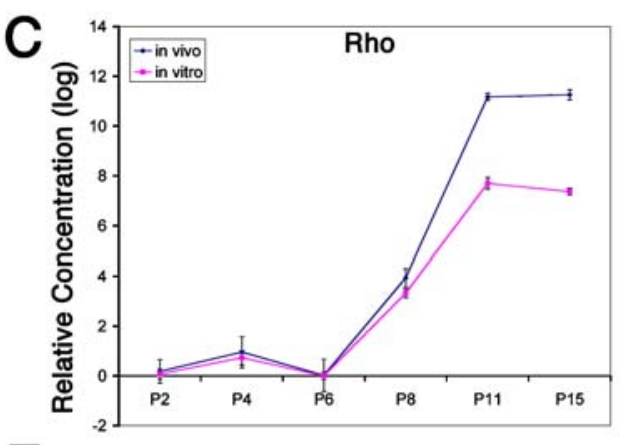

E

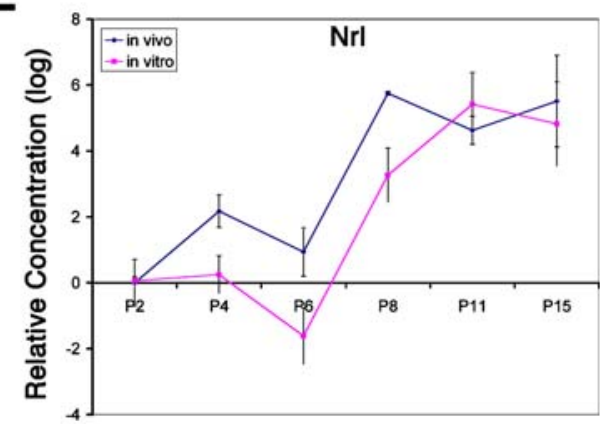

though it kept the same late increased expression pattern. d Twochannel (in vitro vs in vivo) $\log _{2}$ intensity of Nrl gene (BF464350) in microarray, normalized by slide median intensity. PN2 in vivo intensity normalized was set as 1 . The results showed both late expression patterns of $\mathrm{Nrl}$ and the reduced expression level in vitro especially at the early time points. e Quantitative RT-PCR result of Nrl, confirming the increasing expression pattern of Nrl. PN2 in vivo expression level was set as 1 . Nrl showed reduced expression levels in early time points $(p<0.01$ at PN4 and PN6), though it kept the same late increased expression pattern

and in vivo can also distinguish developmental mechanisms that are peculiar to the retinal cells and their microenvironment from those that involve exogenous signals.

A striking result of our study is that $75 \%$ of the 8,800 genes detected on our microarrays showed an unchanged expression ratio between retinal explants and freshly dissected retinas of the same age. Even among the $25 \%$ of genes that showed some difference, many of the differences were shifts in temporal patterns or final levels rather than absolute changes in expression. For example, some genes within the differentially expressed group showed an initial change as soon as the tissue was explanted but then a 
Fig. 8 Alternative expression (log ratio of in vitro/in vivo) of preferentially expressed genes in rod photoreceptors in vitro and in vivo. Group I (a) includes Rom1, Nrl, Tulp1, Prph2, Elov14, and Rcvrn and shows decreased expression levels in the early stages in culture but reaches the same levels as in vivo at later stage; group II (b) includes Rbp3, Mpp4, Gng1, Abca4, and Aip11 and shows no significant changes during in vitro development; group III (c) includes Sag, Kcnj14, Vtn, Rpgrip1, Pde6b, and Rho and shows decreasing expression levels from the early to later stages or reduced levels in the later stages in vitro

gradual recovery to in vivo levels by the end of the period examined. Other genes, particularly some of the rod photoreceptor genes such as Rho, Sag, Rpgrip 1, and Pde6b, showed a time of onset of expression that was very close to the onset in vivo but did not show the large increase in RNA levels seen in vivo during the second postnatal week [17]. This correlates well with the morphological observations that explant cultures do not elaborate extensive rod outer segments [2]. Only about $1 \%$ of all the genes tested showed a change of greater than threefold between the explants and the in vivo retinas. The remarkable similarity between the in vitro and in vivo patterns of gene expression confirms our previous conclusion that much of the postnatal retinal development is regulated by intrinsic factors [2]. Further studies are needed to see if the patterns of gene expression during embryonic stages of development are also comparable in vitro and in vivo.

Ischemia/hypoxia-like responses in early stages of retinal culture

A substantial proportion of the gene expression changes seen in retina explants represents an acute response to environmental changes either just at the early culture stages or throughout the culture period. Many ischemia/hypoxiainducible genes, such as Bnip3 and Stip1, and possible stress-responsible genes, such as Nfat5 and Hspa1l, show increased expression in this stage.

Bnip3 is a proapoptotic member of the Bcl-2 family, and its expression is induced by hypoxia through the hypoxiainducible factor HIF-1alpha. The protein translocates to the nucleus in response to global brain ischemia in the rat hippocampus [18]. Constitutively expressed Bnip3 may participate in apoptotic and necrotic processes following brain ischemia. In MCF-7 cells, epidermal growth factor and insulin-like growth factor effectively protected these cells from Bnip3-induced cell death [19]. This suggests a possible improvement of retina explants through the inhibition of Bnip3.

Stip1 is homologous to the yeast stress-inducible mediator of the heat shock response, Sti1. It is one of the most extensively studied cochaperones and is able to directly associate with both Hsp70 and Hsp90 [20]. Upregulation of the gene has been observed in the retina a

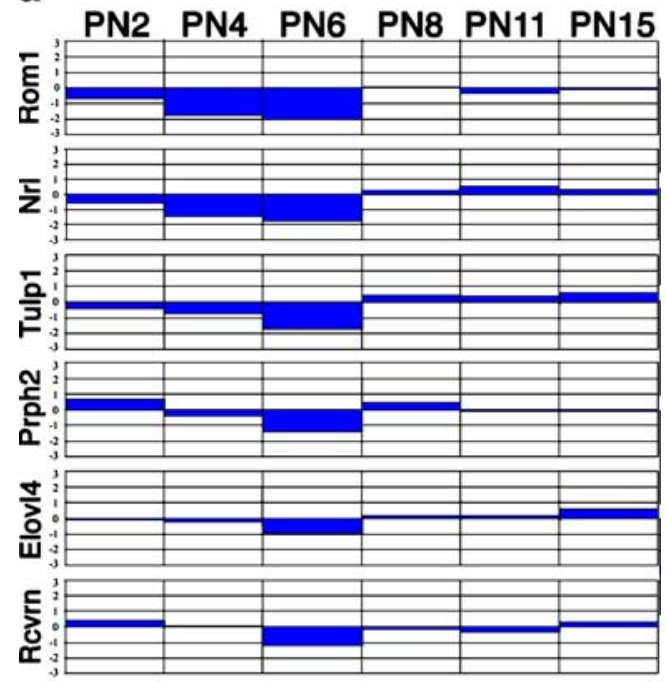

b
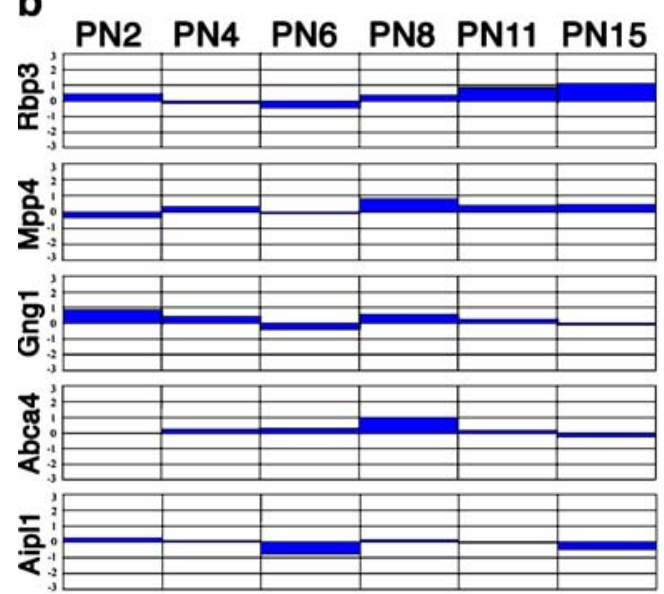

C

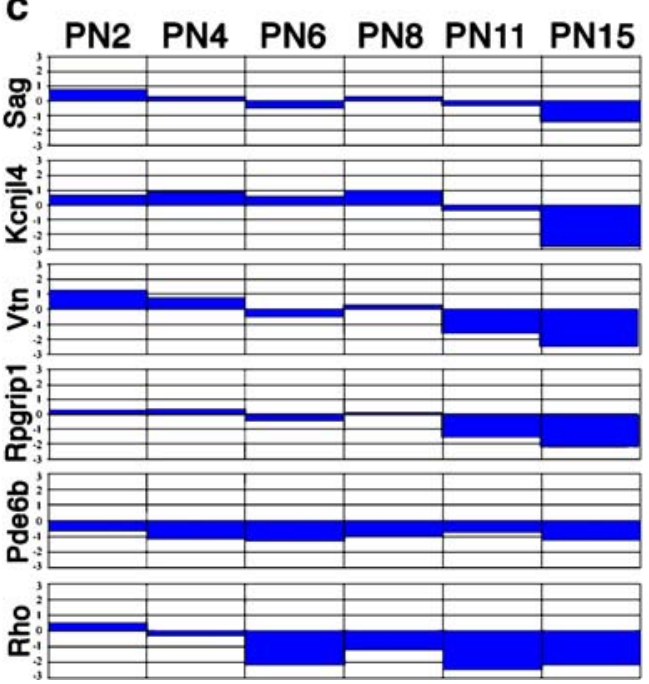

explant. Stip1 has been shown that in response to lipopolysaccharide, the expression of Hop messenger RNA was also increased in both the murine macrophage 
a

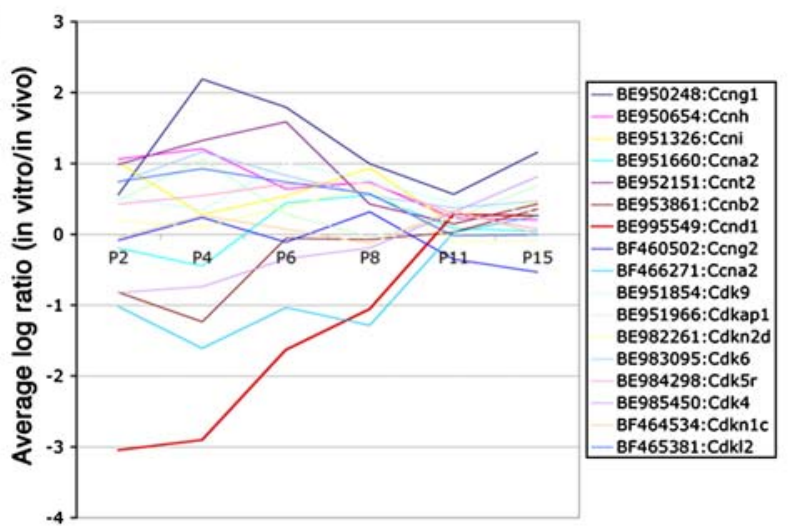

b

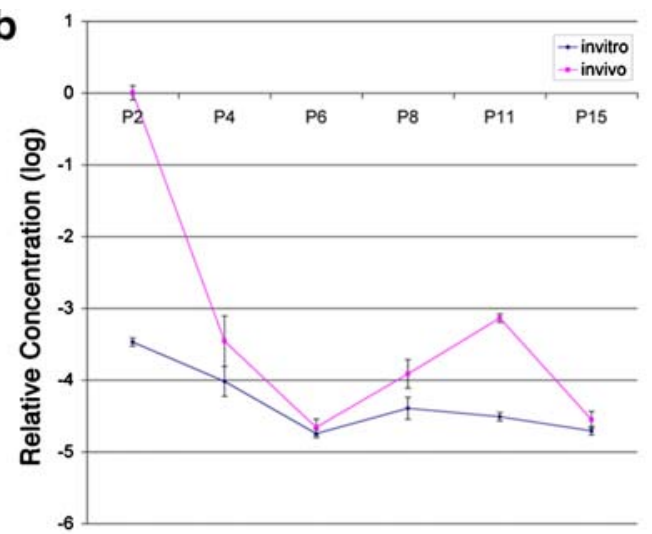

C PN2
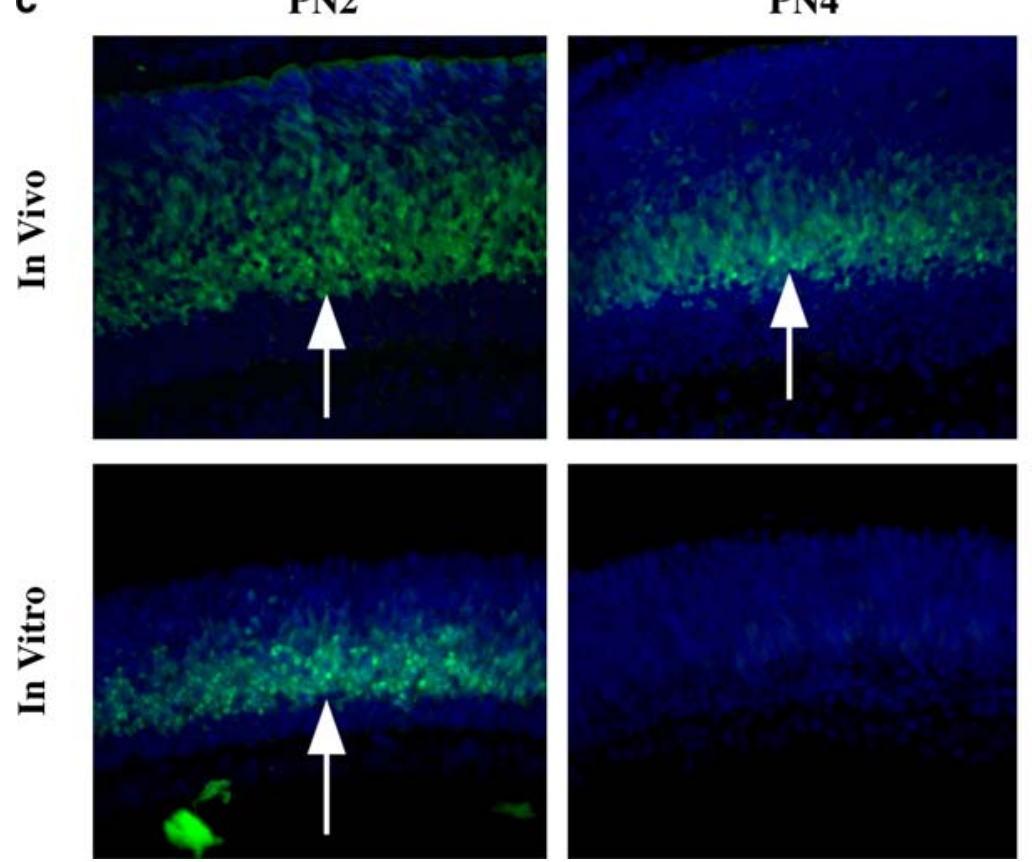

PN6
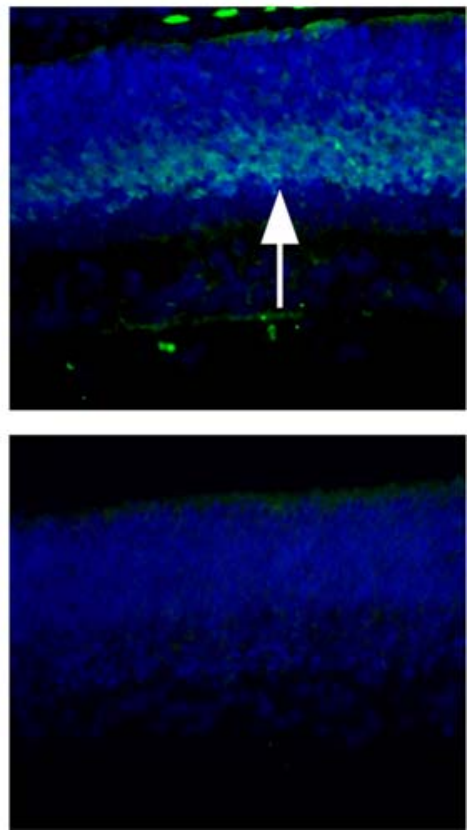

Fig. 9 Early reduction in cell cycle-related gene Ccnd1. a Cyclinrelated genes: All cyclins, cyclin-dependent kinases, and cyclindependent kinase inhibitors tested in the microarray are listed in the chart. Expression changes were greatest at the early time points. A few genes underwent significant expression changes including Ccnd1, which was remarkably downregulated in early time points. b Quantitative RT-PCR confirmation of changes in Ccnd1 expression over the postnatal period. The same expression pattern was seen in both in vitro and in vivo with a significant early reduction at PN2 in the in vitro group $(p<0.0000001)$. $\mathbf{c}$ Immunohistochemical staining of early postnatal stages with anti-Ccnd1 antibody showed Ccnd1 (green fluorescence, white arrows) has a higher level at early time points PN2 and PN4 and then a significant reduction at PN6. The reduction in labeling occurred more rapidly in the cultured retinas. Nuclei were labeled by blue fluorescence

binds to the tumor necrosis factor (TNF) promoter and is a key mediator in the activation of TNF gene transcription during hypertonic stress [25]. The gene for Hspa1l, also known as Hsp70-Hom, is located a region with similarity to Hsp70-1 and was expressed constitutively at a low level but was not induced by heat shock in HeLa cells [26]. Genetic variations of Hspall had significantly higher plasma concentrations of TNF-alpha and interleukin-6 in humans [27]. However, the role of elevation of Nfat5 and Hspall gene expression in retina explants is unclear. 
Alteration of late developmental genes in rod photoreceptors

Previous studies have shown that rod photoreceptors can develop with high fidelity in proper serum-free culture conditions with a normal expression pattern of rod related genes, confirming that retina explant cultures can be used reliably to study rod development [2]. We did, however, note some differences between the in vivo and in vitro systems. Interestingly, the retina-specific transcription factor $\mathrm{Nrl}$, which has a crucial function in rod development [28], had the biggest difference from in vivo expression right at the peak of rod development.

Three different groups of retina-specific genes show distinct patterns of gene expression even though they are all involved in rod photoreceptor development. Previous studies have shown a lack of outer segments and disk formation in the rod photoreceptors of retina explants $[2,4]$. In our studies, the expression of the genes in group I showed a temporal delay at the stage of initiation of rod outer segment formation. Rom1-deficient mice could form photoreceptor outer segments [29] in which Prph2 homotetramers [30] are localized to the disk rims, indicating that peripherin-2 alone is sufficient for both disk and outer segment morphogenesis. However, the disks produced by Rom1-deficient mice were large, and rod outer segments were highly disorganized along with a phenotype, which largely normalized with age. The delay of Prph2 and Rom1 expression in the retina explants could be one of the possible explanations for the dysmorphogenesis of rod outer segments. More recently, actin and Tulp1, one of the other genes in group I, have shown colocalization at the inner segment of the photoreceptor cells, connecting cilium and outer limiting membrane, suggesting that Tulp1 may be involved in actin cytoskeletal functions such as protein trafficking that takes place at or near the plasma membrane from the inner segment through the connecting cilium into the outer segment of photoreceptor cells [31]. Whether the decrease in Tulp1 expression in retina explants is responsible for the lack of formation of rod outer segments is unclear. There is no evidence yet that Elovl4 and Rcvrn, both in this group, are also associated with outer segment morphogenesis. Rpgrip1 in group III of this study, which decreased in the later stage examined, is localized to the photoreceptor connecting cilium and is also required for disk morphogenesis, putatively by regulating actin cytoskeleton dynamics [32]. The decline of any or all of these genes in retina explants could cause abnormal outer segment and disk morphogenesis.

We do not know why groups of genes show a similar pattern of expression in the explants. There was no significant change of Rbp3, Mpp4, Abca4, and Aipl1 in retina explants compared with retina in vivo in group II.
Decreasing expression of Sag, Kcnj14, and Vtn was observed in group III. This suggests that distinct parallel signaling pathways might contribute to rod development. Since rod outer segment development is stunted in explant cultures, it is likely that one or more of these signaling pathways is from extrinsic sources.

Does maintenance of the cell cycle need extrinsic factors in retina?

Most cell cycle-related genes changed in the early postnatal days immediately after the retinas were explanted. A substantial decrease in cyclin D1 (Ccnd1) RNA levels occurred early during in vitro retina development. Cyclin D1 is a critical component in the cell cycle machinery for re-entry into the next cell cycle [14]. In situ hybridization studies of normal mouse embryos revealed an extremely high level of cyclin Dl in the retina, indicating a special dependence of this tissue on cyclin Dl [33]. A lack of cyclin D1 from embryonic stages will lead to a striking decrease in numbers of all retina cell types [15], suggesting that cyclin D1 is critical for retina progenitor expansion. Retinas from cyclin D1-deficient mice were shown to have holes in the formation of the retina photoreceptor layer, increased rod photoreceptor loss, and lack of Müller glia cells [16]. In the present study, expression of cyclin D1 was significantly reduced in retina explants. Early reduction in cyclin D1 in the explants might contribute to the observed reduction in rod and Müller glia production and could be one of the basic elements directly controlling in vitro retina development. Identification of factors maintaining the cyclin D1 levels required for normal retina development in vitro will be of benefit for improving the explant culture system but more importantly will shed light on the basic mechanisms regulating cell number in the retina. It has been shown that Sonic hedgehog, released from retinal ganglion cells, can stimulate proliferation of retinal progenitors [34]. However, cyclin D1 expression dropped within the first day, which was much earlier than the decline of the genes preferentially expressed in ganglion cells, such as Pou4f2, Nefl, and Nef3 in retina explants (data not shown). The early withdrawal of cyclin D1 expression is not likely associated with the loss of retina ganglion cells, suggesting that the external signaling other than Sonic hedgehog might be involved in the maintenance of cyclin D1.

During retina explant isolation, the RPE layer was removed. Whether this removal of RPE in the explant cultures affected rod photoreceptor development or maintenance of cyclin D1 expression in retina is unclear. Factors derived from RPE could play essential roles during induction and expansion of the rod progenitor pool, which needs further studies. 
In summary, we have shown that retinal explants show correct expression of most retinal genes during development. Changed expression of specific genes can be ascribed to an ischemic environment in culture, a change in cell proliferation, and a lack of factors stimulating the later stages of rod photoreceptor maturation.

Acknowledgments We would like to thank Yale Keck Microarray Core for microarray printing support. We thank Adrienne Marable for technical assistance. This work is supported by grants EY13865 (CJB) from the NIH, the David Woods Kemper Memorial Foundation (CJB), the Connecticut Lions Eye Research Foundation, and Research to Prevent Blindness, Inc.

\section{References}

1. Zhang SS, Fu XY, Barnstable CJ. Tissue culture studies of retinal development. Methods 2002;28:439-47.

2. Sparrow JR, Hicks D, Barnstable CJ. Cell commitment and differentiation in explants of embryonic rat neural retina. Comparison with the developmental potential of dissociated retina. Brain Res Dev Brain Res 1990;51:69-84.

3. Seigel GM. The golden age of retinal cell culture. Mol Vis 1999;5:4.

4. Caffe AR, Ahuja P, Holmqvist B, Azadi S, Forsell J, Holmqvist I, et al. Mouse retina explants after long-term culture in serum free medium. J Chem Neuroanat 2001;22:263-73.

5. Zhang SS, Wei J, Qin H, Zhang L, Xie B, Hui P, et al. STAT3mediated signaling in the determination of rod photoreceptor cell fate in mouse retina. Invest Ophthalmol Vis Sci 2004;45:240712.

6. Zhang SS, Liu MG, Kano A, Zhang C, Fu XY, Barnstable CJ. STAT3 activation in response to growth factors or cytokines participates in retina precursor proliferation. Exp Eye Res 2005;81:103-15.

7. Zhang SS, Xu X, Liu MG, Zhao H, Soares MB, Barnstable CJ, et al. A biphasic pattern of gene expression during mouse retina development. BMC Dev Biol 2006;6:48.

8. Zhang SS, Xu X, Li J, Liu MG, Zhao H, Soares MB, et al. Comprehensive in silico functional specification of mouse retina transcripts. BMC Genomics 2005;6:40.

9. Li M, Zhang SS, Barnstable CJ. Developmental and tissue expression patterns of mouse Mpp4 gene. Biochem Biophys Res Commun 2003;307:229-35.

10. Eisen MB, Spellman PT, Brown PO, Botstein D. Cluster analysis and display of genome-wide expression patterns. Proc Natl Acad Sci USA 1998;95:14863-8.

11. Beilharz EJ, Russo VC, Butler G, Baker NL, Connor B, Sirimanne $\mathrm{ES}$, et al. Co-ordinated and cellular specific induction of the components of the IGF/IGFBP axis in the rat brain following hypoxic-ischemic injury. Brain Res Mol Brain Res 1998;59:11934.

12. Rashidian J, Iyirhiaro G, Aleyasin H, Rios M, Vincent I, Callaghan S, et al. Multiple cyclin-dependent kinases signals are critical mediators of ischemia/hypoxic neuronal death in vitro and in vivo. Proc Natl Acad Sci USA 2005;102:14080-5.

13. Swaroop A, Xu JZ, Pawar H, Jackson A, Skolnick C, Agarwal N. A conserved retina-specific gene encodes a basic motif/leucine zipper domain. Proc Natl Acad Sci USA 1992;89:266-70.

14. Sicinski P, Donaher JL, Parker SB, Li T, Fazeli A, Gardner H, et al. Cyclin D1 provides a link between development and oncogenesis in the retina and breast. Cell 1995;82:621-30.
15. Fantl V, Stamp G, Andrews A, Rosewell I, Dickson C. Mice lacking cyclin D1 are small and show defects in eye and mammary gland development. Genes Dev 1995;9:2364-72.

16. Ma C, Papermaster D, Cepko CL. A unique pattern of photoreceptor degeneration in cyclin D1 mutant mice. Proc Natl Acad Sci USA 1998;95:9938-43.

17. Treisman JE, Morabito MA, Barnstable CJ. Opsin expression in the rat retina is developmentally regulated by transcriptional activation. Mol Cell Biol 1988;8:1570-9.

18. Schmidt-Kastner R, Aguirre-Chen C, Kietzmann T, Saul I, Busto $\mathrm{R}$, Ginsberg MD. Nuclear localization of the hypoxia-regulated pro-apoptotic protein BNIP3 after global brain ischemia in the rat hippocampus. Brain Res 2004;1001:133-42.

19. Kothari S, Cizeau J, McMillan-Ward E, Israels SJ, Bailes M, Ens $\mathrm{K}$, et al. BNIP3 plays a role in hypoxic cell death in human epithelial cells that is inhibited by growth factors EGF and IGF. Oncogene 2003;22:4734-44.

20. Odunuga OO, Longshaw VM, Blatch GL. Hop: more than an Hsp70/Hsp90 adaptor protein. Bioessays 2004;26:1058-68.

21. Heine H, Delude RL, Monks BG, Espevik T, Golenbock DT. Bacterial lipopolysaccharide induces expression of the stress response genes hop and H411. J Biol Chem 1999;274:21049-55.

22. Sakudo A, Lee DC, Li S, Nakamura T, Matsumoto Y, Saeki K, et al. PrP cooperates with STI1 to regulate SOD activity in PrPdeficient neuronal cell line. Biochem Biophys Res Commun 2005;328:14-9.

23. Lopez-Rodriguez C, Antos CL, Shelton JM, Richardson JA, Lin F, Novobrantseva TI, et al. Loss of NFAT5 results in renal atrophy and lack of tonicity-responsive gene expression. Proc Natl Acad Sci USA 2004;101:2392-7.

24. Chang Q, Harter TM, Rikimaru LT, Petrash JM. Aldo-keto reductases as modulators of stress response. Chem Biol Interact 2003; 143-144:325-32.

25. Esensten JH, Tsytsykova AV, Lopez-Rodriguez C, Ligeiro FA, Rao A, Goldfeld AE. NFAT5 binds to the TNF promoter distinctly from NFATp, c, 3 and 4, and activates TNF transcription during hypertonic stress alone. Nucleic Acids Res 2005;33:3845-54.

26. Sargent CA, Dunham I, Trowsdale J, Campbell RD. Human major histocompatibility complex contains genes for the major heat shock protein HSP70. Proc Natl Acad Sci USA 1989;86:1968-72.

27. Schroder O, Schulte KM, Ostermann P, Roher HD, Ekkernkamp A, Laun RA. Heat shock protein 70 genotypes HSPA1B and HSPA1L influence cytokine concentrations and interfere with outcome after major injury. Crit Care Med 2003;31:73-9.

28. Mears AJ, Kondo M, Swain PK, Takada Y, Bush RA, Saunders $\mathrm{TL}$, et al. Nrl is required for rod photoreceptor development. Nat Genet 2001;29:447-452.

29. Clarke G, Goldberg AF, Vidgen D, Collins L, Ploder L, Schwarz $\mathrm{L}$, et al. Rom-1 is required for rod photoreceptor viability and the regulation of disk morphogenesis. Nat Genet 2000;25:67-73.

30. Travis GH, Sutcliffe JG, Bok D. The retinal degeneration slow (rds) gene product is a photoreceptor disc membrane-associated glycoprotein. Neuron 1991;6:61-70.

31. Xi Q, Pauer GJ, Marmorstein AD, Crabb JW, Hagstrom SA. Tubby-like protein 1 (TULP1) interacts with F-actin in photoreceptor cells. Invest Ophthalmol Vis Sci 2005;46:4754-61.

32. Zhao Y, Hong DH, Pawlyk B, Yue G, Adamian M, Grynberg M, et al. The retinitis pigmentosa GTPase regulator (RPGR)-interacting protein: subserving RPGR function and participating in disk morphogenesis. Proc Natl Acad Sci USA 2003;100:3965-70.

33. Godbout R, Andison R. Elevated levels of cyclin D1 mRNA in the undifferentiated chick retina. Gene 1996;182:111-5.

34. Wang Y, Dakubo GD, Thurig S, Mazerolle CJ, Wallace VA. Retinal ganglion cell-derived sonic hedgehog locally controls proliferation and the timing of RGC development in the embryonic mouse retina. Development 2005;132:5103-13. 